\title{
The Dilemma of Ideological and Political Education for Normal College Students Majoring in All General Subjects of Rural Primary Schools and Its Countermeasures under the Background of "Internet Plus" -- Taking Guangxi K College as an example
}

\author{
Lei Yanfei ${ }^{1}$ \\ ${ }^{1}$ (School of Education Science in Guangxi Science \& Technology Normal University, Guangxi, Laibin 546199)
}

\begin{abstract}
Based on directed normal junior college students of Guangxi K College, who have graduated from high schools, this paper analyzes the characteristics of normal college students majoring in all subjects of rural primary schools, and puts forward three dilemmas of ideological and political education under the background of the widespread use of the Internet, namely, the ideological and political education is still mainly conducted by teachers, the "Internet Plus" ideological and political education system needs to be innovated, and the "Internet Plus" vocational ideal education is insufficient. In this paper, three ways are put forward to solve the problems, namely, taking students as the main body to build internet platforms, innovating the ways and methods of "Internet plus Ideological and Political Education", and using the internet to strengthen students' vocational emotion education.
\end{abstract}

\section{Introduction}

The term of "normal college students majoring in all subjects of rural primary schools" refers to those students enrolled for free in accordance with the government's targeted training plan for rural teachers majoring in all subjects of primary schools. These students are exempt from tuition and fees during their school period, and can also enjoy living allowances. After graduation, they will obey the arrangement of the local education bureau and return to teach in the rural primary schools of their native places. The normal college students majoring in all subjects of rural primary schools studied in this paper are the students of junior colleges who have graduated from high schools. Guangxi K College, as one of the training institutions undertaking the program in Guangxi, is a national full-time undergraduate college with more than 17300 full-time students, 28 undergraduate majors and 11 junior college majors. Since 2013, the school has started to enroll normal junior college students majoring in all subjects of rural primary schools who have graduated from high schools. The students are mainly rural minority examinees in underdeveloped counties (cities and districts) under the administration of Liuzhou City, Laibin City, Guigang City and other areas in central Guangxi.

\section{The Characteristics of Normal College Students Majoring in All Subjects of Rural Primary Schools}

From 2013 to 2020, the school enrolled a total of 1,918 junior normal college school students majoring in all subjects of rural primary schools. These students have the following characteristics.

\section{(I) Orientation of Career Choice}

According to the spirit of the Notice on the Implementation of the Plan for the Directed Training of Rural Teachers Majoring in All Subjects of Primary School (No. 19 [2013] of Education Department of Guangxi) and Notice on the Directed Training Plan of Rural Teachers Majoring in All Subjects of Primary School, 2020 (No. 3 [2020] of Education Department of Guangxi) issued by Guangxi Zhuang Autonomous Region, the training of three-year junior college students majoring in all subjects of rural primary schools who have graduated from high schools is a kind of directed and commissioned training, which is meant for certain teaching positions. These characteristics are mainly manifested in two aspects. First, the targeted working industry. Students are required to sign the Agreement on Directed Training Plan for General Teachers of Rural primary schools before entrance, in quintuplicate. Students keep one copy for themselves and after they 
meet the graduation requirements and graduate successfully, they have to teach in their local hometown for six years. The career choice of graduates is stipulated in the form of an agreement. Graduates are not allowed to choose their own career freely. In the first six years, they can only engage in the teaching profession according to the requirements of the agreement. Second, the "orientation" of the work places. After graduation, the graduates must return to the place of origin to work, unconditionally obey the arrangement of the local education bureau, and be sent to the primary schools or teaching sites of township and below to teach for six years. This is a requirement for graduates of this major in the workplace.

\section{(II) The skills to teach all subjects}

At present, differentiated training according to different subjects is the mainstream mode for normal college students in China. Under this mode, each normal college student mainly learns the professional knowledge and teaching techniques of one subject, and usually they can only be competent for teaching one or two subjects. However, due to its particularity, rural primary schools need teachers who are competent for multidisciplinary teaching and being the class teachers. According to China Education Daily, "The aging of teachers in rural areas has become a serious problem faced by many rural principals, with a serious structural shortage." "There is a shortage of full-time teachers in music, sports, art and music, and the situation of teachers in rural areas is worrying." [1] Therefore, the school has put forward the training program of "one specialty and many abilities" for general teachers. Specifically, it can be explained as, "In addition to being proficient in one subject, they can also be engaged in the teaching of multiple subjects, and have certain ability to conduct the education management and research of primary schools, as well as the ability of self-development and self-improvement." [2] Under the guidance of this teaching program, this college has set up professional theory courses and teaching skill courses of Chinese, mathematics and English for primary schools, as well as courses like physical education, art, music, dance and computer science, so as to cultivate students' ability of multi-disciplinary teaching.

(III) Complexity of Ethnic Categories and Identity of Emotional Closeness

The normal college students enrolled by this college with free tuitions and fees are mainly from rural minority areas in Liuzhou, Laibin and Guigang of Guangxi, and the ethnic composition of the students is relatively complex. Most of the students grew up in the countryside, so they have deep feelings for the countryside and have a common emotional closeness. In 2020, for example, a total of 339 high school graduates were enrolled in the major of junior college general teachers, including 114 students from ethnic minorities (71 from the Zhuang, 23 from the Dong, 11 from the Miao, 7 from the Yao, 2 from the Mulam and 1 from the Tujia). From these data, it can be seen that the minority component of the specialty is complex. Due to the different growth soil of different nationalities, the different national cultures bred from them will form different ideas and characters, and their value orientation will be different, too. Although there are differences in ethnic culture, most of the students grew up in rural areas, and they have a natural affinity for rural life, production, learning and communication, and the same emotional identity and affective closeness, which is of great benefit to the future teaching work. In 2020, among the 339 junior college students majoring in all subjects of primary schools enrolled by the college, 287 of them are from rural areas, accounting for $85 \%$. These students understand the backwardness of rural education and can resonate with the emotional world of left-behind children, so as to better build rural primary education.

\section{Difficulties in Ideological Education of Directed Normal College Students Majoring in All Subjects of Primary School under the Background of "Internet +"}

With the development and improvement of the internet and the popularization of terminal equipment, most college students have smart phones and computers. They can browse the publicized information of the world. This information is complicated and it's difficult for college students to judge the authenticity of them, which makes ideological education face great challenges.

(I) The Traditional Mode of Teacher-oriented Ideological and Political Education Needs to be Changed

College teachers and counselors are the main body of students' ideological education. In the traditional education environment, education resources are relatively scarce, and the way to learn knowledge is relatively simple. Face-to-face teaching is the main way for teachers. As time passes, knowledgeable teachers become the embodiment of wisdom and authority. In addition, students have been influenced by the Confucian concepts of "He who is virtuous can be a teacher, and he who is well behaved can be a model", "A teacher is someone who passes on knowledge, educates on various subjects, and solves problems." and "respecting the teacher and following moral norms", so that teachers have a high status in the minds of students, and they are very willing to believe and accept teachers' teachings.

In the internet era, after the opening up of online resources around the world, the ethnic minority students from rural areas have got diversified access to information after being equipped with smartphones and computers, and the college is no longer the only provider of education resources. Instead of only relying on teachers to impart more knowledge and skills, students can acquire them through online search engines and social networking platforms. Moreover, with the development of educational ideas, the positions of teachers and students are gradually changing. In colleges and universities, counselors are the main body of ideological education work for students. At the National Ideological and Political Conference, General Secretary $\mathrm{Xi}$ Jinping stressed the need to "guide young people to buckle their first button in life". It can also be seen from 
this that in the internet era, the teachers are also friends of students and, instead of the traditional relationship of knowledge indoctrination, the relationship between teachers and students is now more democratic and equal. Due to their special psychological characteristics and online learning, ethnic minority students majoring in all subjects of primary school will form their own unique understanding. At the same time, influenced and impacted by the diversity of values in the internet era, the ideological and political work will become more and more difficult.

(II) The "Internet Plus" Ideological and Political Education System Needs to be Innovated

"Internet Plus" can be seen early in the Guiding Opinions of the State Council on Vigorously Advancing the "Internet Plus" Action. The article put forward, "Internet Plus is to advocate the connection of all households. It aims to make the in-depth integration of the traditional industry and the internet, and change the traditional thinking mode and ways of learning and living.

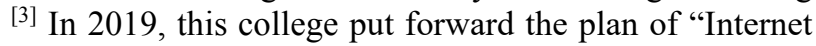
plus Ideological and Political Education", but there are still some problems in the process of specific ideological and political education, which are mainly manifested in three aspects. First, the frequency of use of new media platforms is insufficient. When carrying out ideological and political education, the platforms commonly used by college students such as WeChat official accounts, WeChat moments, Weibo, Yiban, official websites, Tik Tok and Kwai, are not well utilized for ideological education and policy introduction. Second, the existing type of resource in the online ideological and political platform is single, and the function is backward, which can not meet the daily needs of students. The college's existing network ideological and political platforms are mainly Yiban and WeChat official accounts. The information published in publicity windows like WeChat official accounts and Yiban is mainly about party and government activities and student community activities, with single content type (mostly conference and activity news, and few resources on ideological and cultural propaganda), which cannot play a good role as the main ideological and political front in the network; Third, there is a lack of professional teachers to plan, operate and maintain the new media platforms. "Internet plus Ideological and Political Education" has high requirements for talent teams. If there is no relevant talent to join and support, it is difficult to carry out innovation in the online ideological and political education.

(III) The "Internet Plus" Vocational Ideal Education is Insufficient

For the normal college students who major in all subjects of primary students and will work in rural primary schools and teaching sites, they need to have a deeper and comprehensive understanding of their career, including the working environment they will face in the future, the nature of the career, and the meaning of the career. This can help them know their occupation as early as possible, establish the goal of struggle, build firm confidence in the cause of education, and firmly establish the determination to work for the rural primary education.
Only by doing a good job in educating them about their career ideals, can these talents "work there and stay". At present, the vocational ideal education carried out by the college by combining "Internet Plus" is not strong enough, which is shown mainly in two aspects. First, there is a lack of media platforms and online course resources related to vocational ideal education. In the construction process of the network platform for ideological and political education, the college has not set up the vocational ideal education sector separately. Among the courses set up, the situation and policies, mental health education of college students, career planning and employment and entrepreneurship guidance related to career ideal education are rarely recorded into online courses, which are not convenient for students to learn online. Second, it fails to make full use of the advantages of online media to communicate with rural primary schools. Nowadays, the internet is highly developed. After the implementation of balanced education, rural primary schools have also been equipped with internet hardware and software. College students can communicate with rural primary schools by making use of online advantages to further understand the classroom teaching and overview of school management of rural primary schools. In addition to probation and internship, the college has not effectively taken advantage of the connectivity of the internet. It can be said that how to further promote the "Internet Plus" vocational ideal education and help students majoring in all subjects of rural primary schools to set up the correct ideal, so as to achieve the goal of "work there and stay", is a big problem faced by the college under the background of the internet.

\section{Ideological Education Path for Students Majoring in All Subjects of Primary School under the Background of "Internet Plus"}

\section{(I) Respecting Students and Building Good Internet Platforms}

In the process of education, students are the main body, so it is necessary to use new media technology to build good online platforms under the condition of highlighting the dominant position of students. In the era of Internet, students are no longer the objects of unconditional and passive acceptance for teachers in ideological and political education activities, but have become subjects with high self-thinking ability and critical thinking ability. In such an environment, it is necessary to change the mode of ideological and political education from the traditional single teaching mode to the mutual exploration mode, respect students' dominant position, and conduct equal dialogue and communication with students. New media technology can be used to build an equal two-way communication platform, so as to timely and comprehensively understand the learning characteristics and personality of ethnic minority students, provide full and accurate materials for ideological education, and at the same time, convey teachers' ideas in a timely and effective manner. Through 
platforms such as WeChat, Tencent QQ and Weibo, teachers can not only learn about minority students' daily living habits, folk culture, personality characteristics and other relevant information, so as to provide reference for ideological education, but also break the limitation of time and space to help students in time.

We should make full use of the internet, actively carry out online activities with ethnic characteristics, publicize culture with ethnic characteristics, and consolidate the consciousness of the community of Chinese nation. At the Seventh Central Committee Symposium on Work of Tibet, General Secretary Xi Jinping stressed the importance of strengthening ideological and political education in schools, infusing the spirit of patriotism into the whole process of school education at all levels and of all types, and strengthening the sense of ethnic community. We should make full use of the "Internet Plus" thinking, and organize related activities on platforms such as Yiban, WeChat official accounts and school official websites to attract students to participate in special festivals of different ethnic groups. The scope of activities can even be extended to other schools to mobilize the enthusiasm of students to participate in the activities, exercise students' ability and broaden their horizons. The "Internet Plus" thinking should be used to publicize the excellent traditional culture of ethnic minorities, encourage minority college students to express their love for their ethnic groups, stimulate their sense of ownership and national pride, and cultivate students' sound personality.

(II) Innovating the Ways and Methods of "Internet plus Ideological and Political Education"

We should promote the development of new media platforms and create distinctive spaces. College teachers are encouraged to create personal accounts on new media platforms such as WeChat official accounts, Weibo, Tik Tok and Kwai, and to send ideological, political and cultural propaganda articles through social platforms such as Qzone, QQ groups, WeChat moments, confession wall, official accounts, Tik Tok and Kwai. We shall create a "green and healthy" platform that students like, and attract students' participation through online courses, postgraduate entrance exams, part-time jobs, psychological counseling, idle goods trading and other forms of services that teenagers are interested in, as well as online application, online course selection, online leave, online business and other forms that can effectively serve students. We should create a red space of great educational significance, and hold various and comprehensive "red activities" on the Internet. Students will be attracted to participate in the activities for awards, activity points and prizes. The content with positive educational significance, such as red culture, awareness of national community, ideal of the great Chinese dream and the spirit of socialism with Chinese characteristics, will be integrated into the activities to cultivate students' patriotic feelings. Finally we can reach the purpose mentioned in the Opinions of CPC Central Committee and the State Council on Comprehensively Deepening the Reform of the Construction of Teachers in the New Era, namely guiding teachers to establish correct views of history, nation, country and culture, and establishing firm confidence in the path, theory, system and culture of socialism with Chinese characteristics. ${ }^{[4]}$

We should strengthen the construction of new media platforms and enrich their resources. Based on Yiban and WeChat official accounts, we should further utilize Yiban, WeChat official accounts, Tik Tok and other platforms, we should encourage students to publish personal works, improve the review efficiency of comments and attract teachers to contribute articles and reward teachers who publish high-quality articles on these platforms; We should increase the publicity of the platforms, attract parents to join the platforms, and publish works and comment on the works on these platforms, turning the one-man show of school teachers into a big stage for the three-party linkage of "school, family and students".

Strengthen training on the ability of ideological and political personnel to use new media. In the context of the internet, colleges and universities should cultivate counselors' ability to use network media technology, so that they can skillfully use students' communication software, such as WeChat, QQ, Weibo, Baidu Tieba and other social network platforms, and timely understand the ideological trends of students through social platforms such as Qzone, QQ groups, WeChat moments, confession wall, public accounts, Tik Tok and Kwai, and so that they can find and solve problems as soon as possible.

(III) Making Full Use of the Internet to Strengthen Students' Vocational Emotional Education

Mr. Guo Yuanxiang mentioned: "Even if there is the most perfect bill, the wisest directive, and the best textbook, everything would be in vain if the people responsible for implementing are not full of enthusiasm, not full of passion for their mission, and not having faith in the cause." [5] The Opinions of the Ministry of Education and other Five Departments on Strengthening the Construction of Rural Teachers in the New Era mentioned that, to cultivate the feelings of rural education, we should guide teachers to be facilitators and practitioners of rural revitalization and modernization of rural education in rural areas." [6] It can be seen that education is very important for career development of normal college students.

By using the internet technology and relying on online platforms such as Xuexitong, we have set up and recorded online courses about the development of basic education in Guangxi, the management of rural schools, and the professional mission of general teachers, and elements of ideological and political education are integrated into the courses, so that students can learn them at any time. In the process of teaching, we should affirm the importance of primary school general teachers to rural primary school education, emphasize its shortage, find out the value of general teachers together with students, and combine it with our own value pursuit, and establish the lifelong goal of dedication to rural primary schools education.

We can create an online internship platform and link rural primary schools with peer-to-peer online connectivity. Relying on the platforms, without going to the local areas for practice, we can watch the teaching activities of teachers and students in rural primary 
schools online, and communicate with teachers in primary schools online in teaching, head teacher management and other aspects of experience. After getting permission, elementary school students can be given online lessons, online homework correction, online psychological counseling and other activities. In addition, students can bring out the theoretical knowledge they have learned in class and discuss and verify with experienced front-line teachers, so as to recognize their own shortcomings and conduct better self-education, self-shaping, and self-improvement, and shape themselves into people's teachers who are widely liked and loved by students.

With the continuous upgrading of the internet technology, especially the development and improvement of 5G "Internet of Things" technology, the learning and life style of students will be further changed. In line with its trend, a variety of new media platforms will also become a sharp tool for ideological education of college students. As ideological education workers for college students, we should correctly understand the challenges and opportunities brought by the application of Internet, prevent risks, seize the opportunity, constantly explore and innovate the mode of ideological education work, establish and perfect the ideological education mechanism for directed students majoring in all subjects of primary schools under the background of Internet. We also need to firmly guard the position of ideological education in colleges and universities, train socialist builders and successors with sound personality and correct thoughts for the Party and the country.

Fund program: Research on Policy Support and Implementation Effect of Resource Allocation of Rural Teachers in Ethnic Minority Areas, 2018 Western Education Project of the 13th Five-Year Plan of Foundation of National Social Science (XMA180281)

\section{References :}

1. Yi Xin. On the Problem of How Rural Schools Develop in the Serious Structural Shortage of Teachers[N] China Education News, 2013-11-18(2).

2. Guangxi K College , The Professional Training Program of Academic Normal School (Primary General Education) of 2018 Grade

3. The State Council Guidance on Actively Promoting the "Internet" Action (Guofa (2015)40) [EB/OL]. (2015-07-04) [2021-02-15]. http://www.gov.cn/zhengce/content/2015-07/04/con tent $10002 . \mathrm{htm}$.

4. Opinions of the State Council of China on Comprehensively Deepening the Reform of the Construction of Teachers in the New Era [EB/OL].] (2018-01-20)[2021-02-18]. http://www.gov.cn/zhengce/2018-01/31/content_52 62659.htm.

5. Guo Yuanxiang. Curriculum Design and Implementation of Integrated Practical Activities [M]. Beijing: Capital Normal University Press, 2001:48.
6. The Six Departments of the Ministry of Education on Strengthening the Construction of Rural Teachers in the New Era (Teachers [2020] No.5) Organization of the CPC Central Committee of the Ministry of Education, National Development Reform Commission, Ministry of Finance and Ministry of Human Resources and Social Security [EB/OL].] (2020-09-04) [2021-02-22] http://www.gov.cn/zhengce/zhengceku/2020-09/04/ content 5540386.htm.

7. Zhong Li, Liu Binzhi. The United Front Advantages and Strategies in the Prevention and Treatment of Emergencies in Colleges and Universities [J]. The Journal of Chongqing Institute of Socialism 2009(11)

8. Tan Zhisong, Li Yinhui. Construction of Normalization Mechanism of National Unity Education in Ethnic Colleges and Universities[J]. Chinese Ethnic Education 2016(10)

9. Wu Hanlu. An Innovative Study on the Work of Minority Students in Colleges and Universities under the Background of Internet[J]. Modern Commerce and Industry ,2019(2) 